\title{
Well-Being and Help-Seeking Among Assemblies of God Ministers in the USA
}

\section{Kristen M. Kansiewicz ${ }^{1}$ D . James N. Sells ${ }^{2} \cdot$ Daniel Holland ${ }^{2} \cdot$ Donald Lichi $^{3}$. Mark Newmeyer ${ }^{4}$}

Accepted: 17 December 2021 / Published online: 8 January 2022

(c) The Author(s), under exclusive licence to Springer Science+Business Media, LLC, part of Springer Nature 2022

\begin{abstract}
This study examined Assemblies of God pastors in the USA $(n=874)$ on role identity, well-being, religious coping, and attitudes toward seeking professional counseling. Overall, $14.1 \%$ had depression at moderate or higher severity based on the PHQ-9 scale (score of 10 or above), with an additional $25.7 \%$ in the mild category (score of 5-9). On the Clergy Spiritual Well-Being scale, 9.2\% had poor spiritual well-being in everyday life, while $18.1 \%$ showed poor spiritual well-being in ministry (score below 15 on each respective subscale). About $20 \%$ of the sample scored in the high range (above 10) on the Clergy Occupational Distress Index. Male role norms, occupational distress, and positive religious coping were predictive of helpseeking attitudes. Those who were married, younger, more highly educated, female, or had more close friends had more positive attitudes toward seeking counseling.
\end{abstract}

Keywords Clergy $\cdot$ Mental health $\cdot$ Help-seeking $\cdot$ Counseling $\cdot$ Minister health

\section{Introduction}

Mental health in the church is an increasingly prevalent topic in both academic and popular conversation (LCR, 2015). From research studies to blogs and Twitter feeds, many have acknowledged the need to decrease stigma and improve mental health in church settings for both congregants and pastors (ChurchTherapy.com; Grcevich,

Kristen M. Kansiewicz

kansiewiczk@evangel.edu

1 Graduate Counseling Program, Evangel University, 1111 N. Glenstone Ave., Springfield, MO 65802, USA

2 School of Psychology and Counseling, Regent University, Virginia Beach, VA, USA

3 EMERGE Counseling Ministries, Akron, OH, USA

4 Townsend Institute, Concordia University, Irvine, CA, USA 
2018). The widely publicized death of Pastor Jarrid Wilson by suicide in 2019 sharply highlighted the mental health concerns within the church and among pastors. The present study sought to understand the complex factors that relate to clergy well-being and help-seeking attitudes in order to ultimately identify and overcome the potential barriers that prevent pastors from seeking professional counseling.

\section{Factors Influencing Well-Being and Help-Seeking Among Pastors}

Pastors have a variety of occupational and role expectations, many of which are not concretely clear. The complexity of one person serving in multiple functions can produce role ambiguity, dual relationships, poor boundaries, and unacknowledged power differentials between pastors and the congregation (Chen, 2020; Miles \& Proeschold-Bell, 2013; Pooler, 2011). In addition, the vocation of the pastor comes with unique occupational stressors, and many have noted high stress levels among clergy (Hendron et al., 2012; Lee \& Iverson-Gilbert, 2003; McMinn et al., 2005; Miles \& Proeschold-Bell, 2013; Williams, 2019). A study of Assemblies of God ministers in Minnesota showed 65\% were experiencing burnout or bordering on burnout (Visker et al., 2017).

The research on rates of mental illness among clergy is extremely limited. Estimates of depression among ministers range from $11 \%$ to much higher estimates of $41 \%$, while studies have shown that about $13-21 \%$ of pastors have experienced elevated levels of anxiety (Proeschold-Bell et al., 2011, 2013). Using the Patient Health Questionnaire-9 (PHQ-9) and the Hospital Anxiety and Depression Scale-Anxiety (HADS-A) for a sample of 1726 United Methodist ministers, Proeschold-Bell et al. (2013) found $11.1 \%$ met the screening criteria for major depression and $13.5 \%$ had levels of anxiety above normal thresholds. These rates were higher for clergy who had been in ministry longer (above the mean of 17 years). Knox et al. (2002) found even higher rates $(20 \%)$ of Catholic clergy meeting or exceeding depression cutoffs on the Center for Epidemiological Studies depression scale.

Spiritual well-being plays a key role in overall clergy well-being and vocational functioning (Ellison et al., 2010). Factors such as attachment to God, using prayer or Bible study to personally cope with stress, and maintaining a strong sense of calling to the ministry are all components of clergy spiritual well-being (Bickerton et al., 2015). Spiritual well-being relates to coping strategies for ministers as well. Visker et al. (2017) found that the most frequent coping mechanism for ministers was "religious coping" such as prayer or seeking spiritual meaning (p. 955). Other studies validate this finding, emphasizing the role of personal spiritual practices in pastors' overall approach to coping (McMinn et al., 2005; Milstein et al., 2019; Pargament et al., 2001).

\section{Attitudes Toward Seeking Professional Counseling}

The review of the literature suggests that pastors could benefit from professional counseling due to role confusion, stress, depression, and challenges to spiritual wellbeing and coping. Meek et al. (2003) wrote, "Because of the great demands pastors 
face, there will undoubtedly always be a need for counseling" (p. 344). A key unanswered question is whether or not ministers want this professional help. Seminal studies by Good et al. (1989), Good and Wood (1995), and Levant et al., (2009, 2011, 2013) have established that there are clear differences in help-seeking along gender lines, with women having more favorable attitudes toward seeking professional help than men. Good et al. (1989) explored the impact of traditional male norms on seeking professional help, finding that those who hold more traditional views of male roles are significantly less likely to seek professional help (p. 299). These limiting factors to help-seeking are present for the clergy population that is primarily male and holds traditional views on gender roles.

As previously noted, pastors most often rely on personal and spiritual self-care, followed by family support, and least often seek help from community supports such as counseling or social work services (McMinn et al., 2005; Shirey, 2001, p. 99; Trihub et al., 2010). McMinn et al. (2005) pointed out, "If clergy draw mostly on intrapersonal forms of coping, then it is reasonable to assume that they are reticent to seek help from counselors and psychotherapists" (p. 577). Trihub et al. (2010) found that pastors value sabbaticals and prayer/support groups significantly more than individual or family counseling (p. 106).

\section{Purpose of the Study}

The purpose of this study was to determine whether role identity (caregiver and gender), well-being (occupational distress, current depression level, and spiritual wellbeing), positive or negative religious coping, and demographic factors predicted attitudes toward seeking professional counseling among Assemblies of God ministers in the USA. This study also compared well-being and help-seeking variables between demographic groups. The university's Human Subjects Review Committee granted permission for this study prior to data collection. Permission was granted for the use of scales by the original researchers except for scales that are in the public domain.

\section{Method}

The researchers used purposeful sampling to distribute an online survey via SurveyMonkey (https:/surveymonkey.com) to Assemblies of God pastors. The survey was comprised of demographic questions and seven previously validated scales, following the examples of Milstein et al. (2019) in research with a clergy population. Table 2 displays a summary of the scales, ranges, and categorical cutoffs for each scale. The Caregiver Role Identity Scale is a 9-item scale created by Siebert and Siebert (2005) measures perceptions of oneself as a caregiver as well as beliefs about other people's views of oneself. Exploratory and confirmatory factor analysis showed goodness of fit $(\mathrm{GFI}=0.97)$ with a Chronbach's alpha of 0.81 . The scale has been useful in previous research on individuals serving in helping professions (Siebert \& Siebert, 2007). 
The Male Role Norms Inventory-Very Brief (MRNI-VB; McDermott et al., 2019), is a five-item scale that improved upon a previous 21 -item version. The MRNI-VB measures whether a subject adheres to traditional norms assigned to male roles. The five-item scale showed equivalence in validity and reliability when compared to the 21-item measure, with a Chronbach's alpha of 0.83 .

The Clergy Occupational Distress Scale (CODI) was developed by Frenk et al. (2013) in order to measure unique occupational stressors within a clergy population. Validity and reliability for this five-item scale were examined using two different clergy populations, with Chronbach's alpha values of 0.77 and 0.82 . The exploratory factor analysis showed consistency in variables loading onto one factor. Further, occupational distress as measured by this scale was shown to have a positive relationship with depression symptoms (Frenk et al., 2013). The scores on the CODI range from 0 to 15 and were categorized into low (0-4), moderate (5-9), and high (10-15) for the purpose of descriptive statistics based on the work of Milstein et al. (2019) and evaluation of means and standard deviations.

The Patient Health Questionnaire-9 (PHQ-9) is frequently used in clinical settings and has been cited throughout the research literature (Kroenke et al., 2001). The 10-item PHQ-9 has high internal validity with a Chronbach's alpha of 0.89, along with excellent test-retest reliability. Construct validity is also strong, and the PHQ-9 is considered accurate for diagnosing clinical depression ranging 0 to 27 with severity ranges of minimal 1-4, mild 5-9, moderate 10-14, moderately severe 15-19, and severe 20-27 per scoring instructions (Kroenke et al., 2001).

The Clergy Spiritual Well-Being Scale was developed by researchers at the Duke Clergy Health Initiative in order to overcome problems in using traditional spiritual well-being measures with clergy populations (Proeschold-Bell et al., 2014). These researchers noted a tendency for pastors to score high on spiritual well-being measures due to their significant engagement in religious activities, even though these activities did not necessarily reflect well-being in clergy populations. This 12-item instrument measures a minister's experience of God in both everyday life and in ministry, with two distinct six-item subscales. The analysis of the measure showed significance in goodness of fit for the two-factor model $\left(\chi^{2}=1,712.34\right.$, df $=246$, $\mathrm{p}<0.0001, \mathrm{CFI}=0.97, \mathrm{TLI}=0.97, \mathrm{RMSEA}=0.06$; Proeschold-Bell et al., 2014, $\mathrm{p}$. 886). The scale showed strong model fit and reliability between two data collection points, but a Chronbach's alpha has not yet been reported for either subscale. The subscales negatively correlated with depression, anxiety, and stress measures (Milstein et al., 2019; Proeschold-Bell et al., 2014). In order to determine thresholds for poor spiritual well-being, scores were categorized into poor, moderate, and excellent based on both subscale means and approximate standard deviations (score of $20 \pm 5$ ). Approximately corresponding with the responses of never to sometimes, often to frequently, and always, we established ranges of 6-14 for poor, 15-25 for moderate, and 26 and above for high spiritual well-being.

The Brief Religious Coping Scale (RCOPE; Pargament et al., 2011) is a 14-item scale designed to measure both positive and negative use of religious coping strategies such as praying, assigning spiritual meaning to events, and seeking support from the church. The original RCOPE consisted of 105 items that were rooted in a strong theoretical basis using prior studies on religious coping strategies. Given 
the length of the original scale, a briefer version was deemed necessary for inclusion in further research. The Brief RCOPE showed evidence of a two-factor model with goodness of fit as well as strong validity and internal consistency, with a mean Chronbach's alpha of 0.92 for the positive religious coping factor and 0.81 for negative religious coping. Further, this scale was tested across a wide range of populations showing strong cross-cultural validity and reliability. The two subscales (Positive and Negative) are not combined for scoring and were treated as distinct parts without categorical ranges.

The Attitudes Toward Seeking Professional Psychological Help-Short Form (ATSPPH-SF) was developed twenty-five years after the original 29-item measure was created (Fischer \& Farina, 1995). The short-form version contains just ten items and both versions have been used widely throughout the literature (Elhai et al., 2008). The ATSPPH-SF has strong validity and reliability (Fischer \& Farina, 1995), with secondary analysis confirming validity (Chronbach's $\alpha=0.77$ ) and reliability in populations of college students as well as medical patients (Elhai et al., 2008). This second exploratory factor analysis showed goodness of fit in a two-factor model, measuring both openness to seeking mental health treatment as well as perceptions about the overall value of professional mental health services (Elhai et al., 2008, p. 326).

On the ATSPPH scale, Simpson (2006) provided a rationale for changing the terms "psychologist" and "psychotherapy" to "licensed counselor" and "counseling" due to her population's familiarity with counseling over psychology. The same is true in the Assemblies of God where "professional counseling" is used more frequently than "psychological help." Thus, the present study imitated Simpson's (2006) version of the scale with some additional changes, and the exact scale items used in this study can be found in Appendix A. This adapted version of the scale was referred to in this study's results and discussion as the Attitudes Toward Seeking Professional Counseling (ATSPC) scale or as a variable named "Attitudes Toward Counseling." The ATSPC scale showed good reliability with the present sample (Chronbach's $\alpha=0.84$ ).

The survey contained one additional question: "Please indicate the number of friends you have (not including your spouse) that you can talk to about things that are on your mind or bothering you."

\section{Population and Sampling}

There are 67 regional and language districts in the US Assemblies of God. These districts cover the mainland and non-contiguous US states as well as Puerto Rico. The language districts are also within the geographical confines of the USA but network Assemblies of God pastors who share a non-English primary language (such as Spanish or Korean). In total, there are approximately 18,620 Assemblies of God pastors in the USA within 38,200 total credential holders who may have other job titles such as missionary or para-church organization leader (Assemblies of God, 2018). The lead researcher contacted the office of each district superintendent to request assistance in disseminating the survey to pastors via email and/or social 
media. The language districts were contacted twice in order to improve diversity in the study. In total, 21 regional districts and three language districts chose to respond to the request for participation and distributed the survey to their pastors. Participants completed the survey on their own electronic device such as a smartphone, tablet, laptop, or desktop computer. The survey was available over a six month period from June 2020 to December 2020.

\section{Statistical Analyses}

In addition to descriptive statistics on well-being variables, the present study used multiple regression in order to determine whether the independent variables were predictive of attitudes toward seeking professional counseling. Pearson's- $r$ determined any correlations between the variables. MANOVA and ANOVA compared attitudes toward seeking professional counseling and well-being variables across demographic categories.

\section{Results}

\section{Demographics}

This sample of Assemblies of God pastors $(n=874)$ was made up of $611(69.9 \%)$ lead or senior pastors and $263(30.1 \%)$ associate or staff pastors from across seven geographic regions covering nearly all of the mainland USA. Age was presented categorically, so a mean age could not be calculated. However, 288 (33.0\%) were under age 45 and 586 (67.0\%) were 45 years or older. Four hundred seventy-nine (54.8\%) were between 45 and 64 . This suggests a likely mean age similar to other clergy studies (between 51 and 55 years of age). Seven hundred six (80.8\%) were male, while $168(19.2 \%)$ were female, and 801 (91.6\%) were married. The sample was primarily White $(762,87.2 \%)$. For purposes of comparison, in 2017 the Assemblies of God reported $65 \%$ of their credential holders were White (Assemblies of God, 2017) and as of $201875 \%$ of Assemblies of God credential holders were male (Assemblies of God, 2018). Most of the sample worked as a full-time, paid employee $(649,74.3 \%)$ and $457(52.3 \%)$ earned between $\$ 30,000$ and $\$ 75,000$ per year. Five hundred ninety-five $(68.1 \%)$ had obtained a Bachelor's degree or higher. Regarding social support, 278 (31.8\%) were solo pastors with no coworkers and 75 $(8.6 \%)$ reported having no close friends. Additional demographic information is provided in Table 1.

\section{Data Cleaning and Assumptions Testing}

All analyses were completed in IBM SPSS Statistics (version 27). Data were screened for case exclusionary criteria, outliers, and violations of statistical assumptions. Of the 1,048 completed surveys, 34 cases were determined to be univariate or multivariate outliers on one or more of the nine scales based on histogram plots 
Table 1 Demographics

\begin{tabular}{|c|c|c|}
\hline Item & Frequency & Percentage $(\%)$ \\
\hline \multicolumn{3}{|l|}{ Job title } \\
\hline Lead/Senior Pastor & 611 & 69.9 \\
\hline Associate/Executive/Staff Pastor & 263 & 30.1 \\
\hline \multicolumn{3}{|l|}{ Age in years } \\
\hline $18-24$ & 12 & 1.4 \\
\hline $25-34$ & 106 & 12.1 \\
\hline $35-44$ & 170 & 19.5 \\
\hline $45-54$ & 226 & 25.9 \\
\hline $55-64$ & 253 & 28.9 \\
\hline 65 or older & 107 & 12.2 \\
\hline \multicolumn{3}{|l|}{ Gender } \\
\hline Male & 706 & 80.8 \\
\hline Female & 168 & 19.2 \\
\hline \multicolumn{3}{|l|}{ Marital status } \\
\hline Married & 801 & 91.6 \\
\hline Non-married & 73 & 8.4 \\
\hline \multicolumn{3}{|l|}{ Race } \\
\hline White & 762 & 87.2 \\
\hline Non-White & 112 & 12.8 \\
\hline \multicolumn{3}{|l|}{ Region of the US } \\
\hline Northeast & 271 & 31.0 \\
\hline Southeast & 110 & 12.6 \\
\hline North central & 61 & 7.0 \\
\hline South central & 171 & 19.6 \\
\hline Northwest & 32 & 3.7 \\
\hline Southwest & 80 & 9.2 \\
\hline Great lakes & 133 & 15.2 \\
\hline Language district & 16 & 1.8 \\
\hline \multicolumn{3}{|l|}{ Education levell } \\
\hline High school & 75 & 8.6 \\
\hline Comm. college or Bible college & 204 & 23.3 \\
\hline Bachelor's degree & 366 & 41.9 \\
\hline Master's degree & 177 & 20.3 \\
\hline Doctorate & 52 & 5.9 \\
\hline \multicolumn{3}{|l|}{ Employment status } \\
\hline Full-time paid & 649 & 74.3 \\
\hline Part-time paid & 133 & 15.2 \\
\hline Full-time unpaid & 38 & 4.3 \\
\hline Part-time unpaid & 54 & 6.2 \\
\hline \multicolumn{3}{|c|}{ Salary as Pastor (incl. housing allowance) } \\
\hline Under $\$ 15,000$ & 178 & 20.4 \\
\hline$\$ 15,000-\$ 29,999$ & 114 & 13.0 \\
\hline
\end{tabular}


Table 1 (continued)

\begin{tabular}{lll}
\hline Item & Frequency & Percentage (\%) \\
\hline$\$ 30,000-\$ 49,999$ & 230 & 26.3 \\
$\$ 50,000-\$ 74,999$ & 227 & 26.0 \\
$\$ 75,000-\$ 99,999$ & 85 & 9.7 \\
Over $\$ 100,000$ & 40 & 4.6 \\
Presence of Coworkers & & \\
Solo pastor & 278 & 31.8 \\
At least one pastoral coworker & 596 & 68.2 \\
Number of close friends & & \\
0 & 75 & 8.6 \\
1 & 107 & 12.2 \\
2 & 202 & 23.1 \\
3 & 175 & 20.0 \\
4 or more & 315 & 36.1 \\
Total & 874 & 100 \\
\hline
\end{tabular}

as well as calculating the $p$-value of the Mahalanobis distance in SPSS (cases with a $p$-value less than 0.01 were removed, critical $\chi^{2}=23.59$ ). Fourteen cases were removed due to not holding current credentials with the Assemblies of God. One hundred twenty-six cases were removed due to holding a job title other than "pastor" $(n=874)$. This sample represents approximately $4.70 \%$ of the total national population of Assemblies of God pastors, and about 9.28\% of pastors whose districts distributed the survey.

All scales/subscales were tested for normal distribution and skewness, falling between -0.50 and 0.50 except for the PHQ-9 (skewness = 1.27) and the Brief RCOPE Negative subscale (skewness $=1.63$ ) which were skewed to the left. This skewness made sense given that the overall rates of depression and negative coping were low for the majority of the sample. These scales were retained for analysis due to similarity in skewness for all groups, allowing for accurate comparison. Q-Q plots for all scales showed good linearity after removal of outliers. There were no apparent concerns with multicollinearity, homogeneity of variance, or homoscedasticity.

Sample size for demographic groups was taken into account for ANOVA and MANOVA testing, with limitations on race and marital status comparisons due to unequal cell sizes. These variables were reclassified as dichotomous variables (White and non-White, married and non-married) in order to improve groups sizes to include in comparisons. Number of coworkers was also changed to a dichotomous variable named "Presence of Coworkers" to separate solo pastors from those with any pastoral coworkers.

\section{Means and Scale Ranges}

The scales used in this study are sometimes scored differently as documented in the literature. For example, Frenk et al. (2013) scored the CODI with a possible range 
of 5-20, while Milstein et al. (2019) scored the CODI with a range from 0 to 15 . These differences were accounted for when comparing the results of this study with previous research. Table 2 displays the mean scores for each scale for the full sample along with the standard deviation, range, and categorical cutoffs. These data are provided for the purposes of comparison in future research.

\section{Well-Being Across the Entire Sample}

Descriptive statistics provided the rates of depression, poor spiritual well-being, and high occupational distress levels for the sample as a whole. The means for the PHQ-9, and both subscales of the CSWB scale, and the CODI were provided previously in Table 2. The PHQ-9 scores were skewed to the left, with $526(60.2 \%)$ showing no depression (score of 4 or less). Two hundred twenty-five (25.7\%) fell in the mild depression range (score of 5-9), while 91 (10.4\%) had moderate levels of depression, $25(2.9 \%)$ had moderately severe depression, and $7(0.8 \%)$ showed levels of severe depression. Isolating question 9 which screens for suicidal ideations, $42(4.8 \%)$ of the sample indicated thoughts of self-harm or being better off dead on several days or more in the prior two weeks. Figure 1 displays the categorical data for the PHQ-9.

Spiritual well-being was measured by the two subscales of the CSWB scale: Power and Presence of God in Everyday Life and Power and Presence of God in Ministry. These subscales were not combined for analysis, and for both subscales a high score indicates more positive spiritual well-being. Eighty $(9.2 \%)$ of the participants showed poor spiritual well-being in daily life, while $158(18.1 \%)$ had poor spiritual well-being in ministry. Figures 2 and 3 display the categorical data for both subscales of the CSWB.

Table 2 Scale Means, Standard Deviations, and Ranges

\begin{tabular}{|c|c|c|c|c|}
\hline Variable & Mean & SD & Possible range & Categorical ranges \\
\hline $\begin{array}{l}\text { Attitudes toward seeking coun- } \\
\text { seling }\end{array}$ & 20.78 & 5.70 & $0-30$ & N/A \\
\hline Caregiver role identity & 32.21 & 4.97 & $9-45$ & N/A \\
\hline Male role norms & 17.78 & 5.25 & $5-35$ & N/A \\
\hline Occupational distress & 6.82 & 3.13 & $0-15$ & Low 0-4, Mod. 5-9, High 10-15 \\
\hline Depression level & 4.56 & 4.47 & $0-27$ & $\begin{array}{l}\text { Minimal 1-4, Mild 5-9, Mod. } \\
\text { 10-14, Mod-severe 15-19, } \\
\text { Severe 20-27 }\end{array}$ \\
\hline $\begin{array}{l}\text { Clergy spiritual well-being in } \\
\text { everyday life }\end{array}$ & 21.01 & 4.76 & $6-30$ & $\begin{array}{l}\text { Poor 6-14, Mod. 15-25, Excellent } \\
26+\end{array}$ \\
\hline $\begin{array}{l}\text { Clergy spiritual well-being in } \\
\text { ministry }\end{array}$ & 19.76 & 5.22 & $6-30$ & $\begin{array}{l}\text { Poor 6-14, Mod. 15-25, Excellent } \\
26+\end{array}$ \\
\hline Positive religious coping & 21.84 & 3.63 & $7-28$ & N/A \\
\hline Negative religious coping & 8.86 & 1.95 & $7-28$ & $\mathrm{~N} / \mathrm{A}$ \\
\hline
\end{tabular}

$n=874$ 
Depression Scores by Category

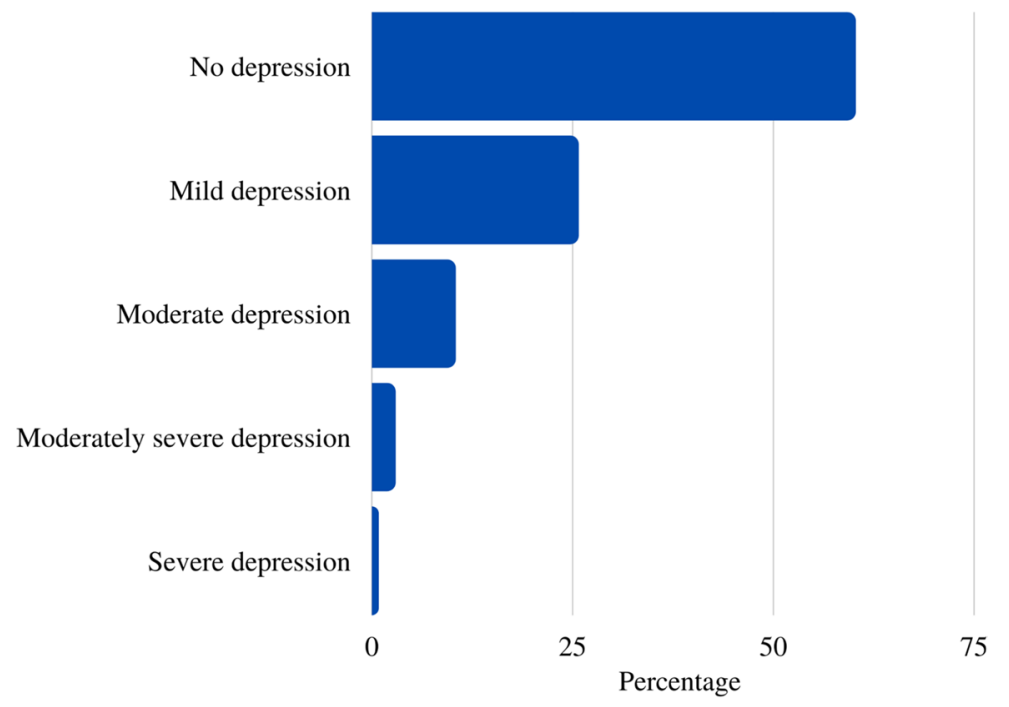

Fig. 1 Depression Scores by Category. Note. None-60.2\%, Mild-25.7\%, Moderate-10.4\%, Mod.severe-2.9\%, Severe- $0.8 \%$

Power and Presence of God in Everyday Life Subscale by Category

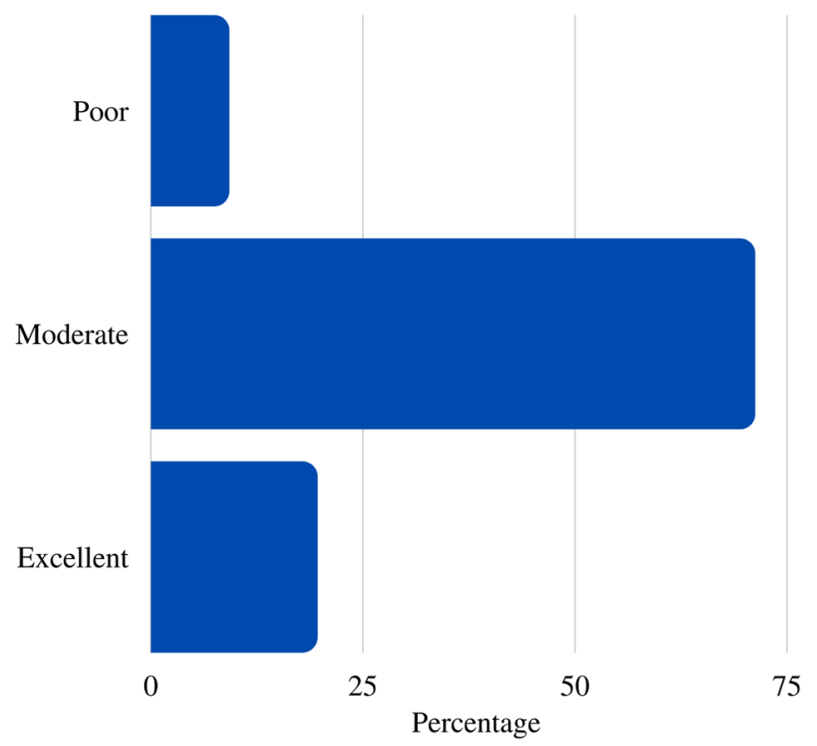

Fig. 2 Power and Presence of God in Everyday Life Subscale by Category. Note. Poor-9.2\%, Moderate- $71.2 \%$, Excellent- $19.6 \%$ 
Power and Presence of God in Ministry Subscale by Category

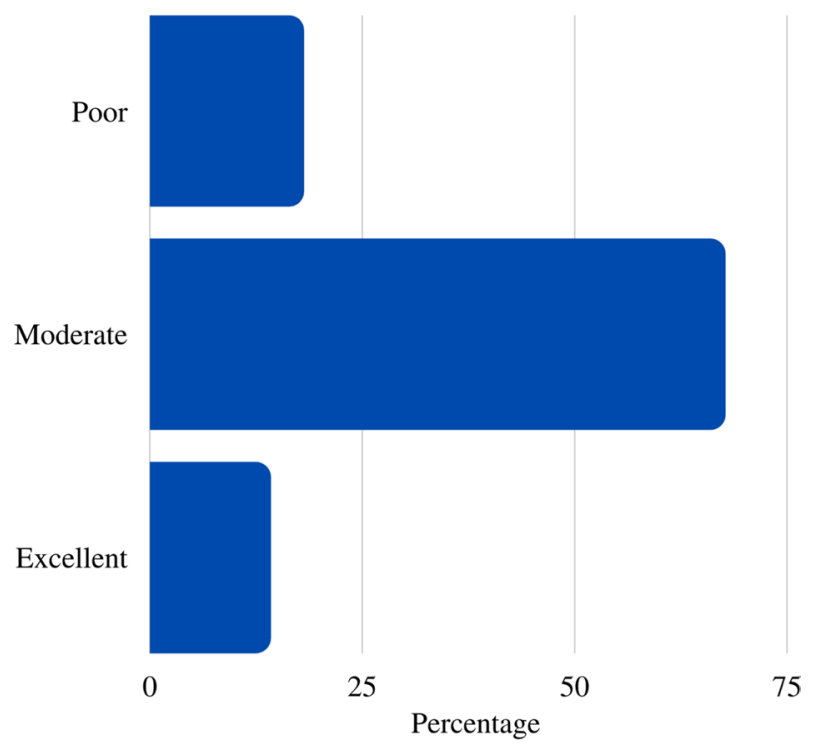

Fig. 3 Power and Presence of God in Ministry Subscale by Category. Note. Poor-18.1\%, Moderate- $67.7 \%$, Excellent- $14.2 \%$

The Clergy Occupational Distress Index (CODI) determined rates of occupational distress for this sample. Following the examples set by Frenk et al. (2013) and Milstein et al. (2019) in categorizing and interpreting CODI scores, we separated CODI scores into categories of low (0-4), moderate (5-9), and high (10-15). One hundred seventy-nine $(20.5 \%)$ of the participants showed high levels of occupational distress. An additional $511(58.5 \%)$ showed moderate occupational distress. Figure 4 displays the categorical CODI results.

A correlational analysis showed multiple significant relationships between the well-being variables. All of the well-being variables showed significant relationships with each other. Table 3 displays these correlations, all of which had significance at a level of $p<0.001$. A multiple regression analysis determined whether occupational distress and spiritual well-being were predictive of depression. The overall regression was significant $(\mathrm{F}(3,870)=142.27, p<0.001)$, and specifically occupational distress $(\beta=0.71, p<0.001)$ and spiritual well-being in everyday life $(\beta=-0.16$, $p<0.001$ ) were significant predictors for depression. Clergy spiritual well-being in ministry was not a significant predictor of depression.

\section{Attitudes Toward Counseling}

Finally, we sought to determine the significance of combined predictors of helpseeking attitudes using stepwise multiple regression. After conducting exploratory Pearson's correlations and ANOVAs, the following predictors were input as likely 


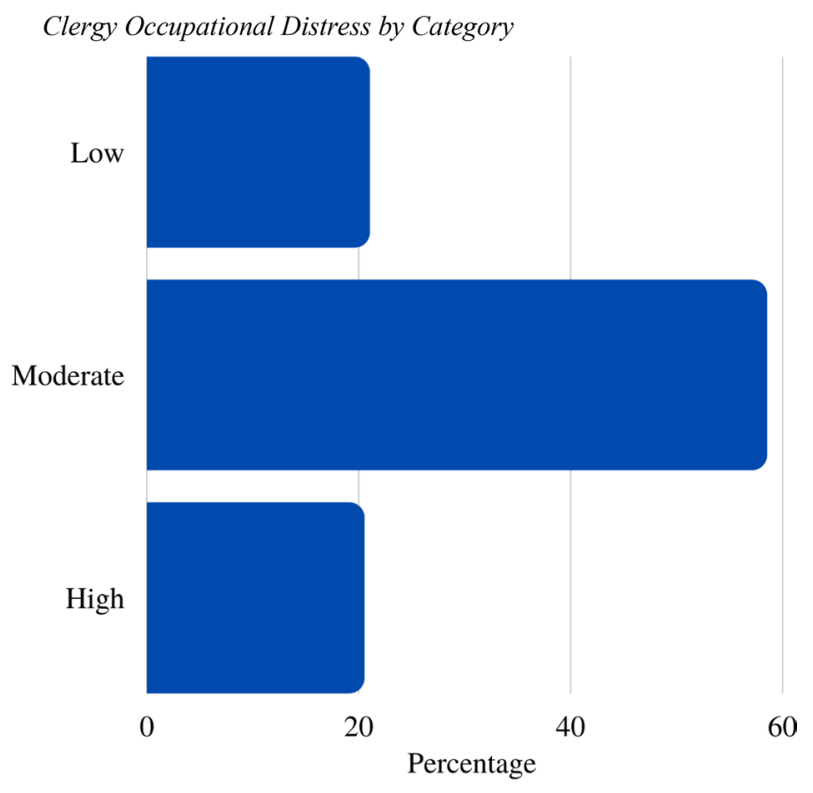

Fig. 4 Clergy Occupational Distress by Category. Note. Low-21.0\%, Moderate-58.5\%, High-20.5\%

Table 3 Significant Correlations Between Well-Being Variables

\begin{tabular}{lll}
\hline Variable 1 & Variable 2 & Pearson's $r$ \\
\hline Occupational distress & Spiritual well-being in everyday life & $-.16^{* * *}$ \\
Occupational distress & Spiritual well-being in ministry & $-.14^{* * *}$ \\
Occupational distress & Depression & $.53^{* * *}$ \\
Spiritual well-being in everyday life & Spiritual well-being in ministry & $.73^{* * *}$ \\
Spiritual well-being in everyday life & Depression & $-.29^{* * *}$ \\
Spiritual well-being in ministry & Depression & $-.25^{* * *}$ \\
\hline
\end{tabular}

$* * * p<.001$

predictors of help-seeking attitudes: MRNI-VB, CODI, Brief RCOPE Positive subscale, age, gender, marital status, education level, and number of close friends. Assumptions testing showed acceptable tolerance levels $(<1.00)$ and VIF values did not exceed 1.20.

In a multivariable model, the combined variables were predictive of help-seeking attitudes, (Adjusted $R^{2}=0.19, \mathrm{~F}(7,866)=30.28, p<0.001$ ). All variables were individually significant predictors of attitudes toward seeking professional counseling $(p<0.05)$. Male role norms, which was inversely related to attitudes toward seeking professional counseling $(r=-0.37, p<0.001)$, were the strongest predictor explaining $13.5 \%$ of the variance $(t=-10.87, p<0.001, \beta=-0.37, \mathrm{SE}=0.03)$. Number of close friends explained an additional $1.5 \%$ of the variance and the remaining variables each explained smaller amounts of the variance. 
Post hoc analysis showed that female participants and those who were married had more positive attitudes toward seeking professional counseling. Age, education level, and number of close friends also showed significant differences in attitudes toward seeking professional counseling. Table 4 displays the ANOVA results. These attitudes toward help-seeking decreased with age, increased with education level, and increased with a minister's number of close friends.

\section{Discussion}

\section{Well-Being Comparisons}

It was hypothesized that Assemblies of God pastors would have similar rates of depression, occupational distress, and spiritual well-being to previously reported findings (Frenk et al., 2013; Milstein et al., 2019). Comparing demographic

Table 4 Significant demographic differences on attitudes toward seeking counseling

\begin{tabular}{|c|c|c|c|c|}
\hline Demographic Variable & Mean & $\mathrm{SD}$ & $\mathrm{F}$ & $p$-value \\
\hline \multicolumn{5}{|l|}{ Marital status (Y/N) } \\
\hline Married & 20.84 & 5.67 & 4.30 & .04 \\
\hline Not married & 20.16 & 6.02 & & \\
\hline \multicolumn{5}{|l|}{ Age } \\
\hline $18-24$ & 22.33 & 5.68 & 4.71 & $<.001$ \\
\hline $25-34$ & 21.17 & 5.02 & & \\
\hline $35-44$ & 22.25 & 5.33 & & \\
\hline $45-54$ & 21.08 & 5.31 & & \\
\hline $55-64$ & 19.92 & 5.95 & & \\
\hline $65+$ & 19.34 & 6.45 & & \\
\hline \multicolumn{5}{|l|}{ Gender } \\
\hline Male & 20.51 & 5.74 & 4.07 & .04 \\
\hline Female & 21.95 & 5.36 & & \\
\hline \multicolumn{5}{|l|}{ Education level } \\
\hline High school & 19.36 & 5.81 & 2.52 & .04 \\
\hline $\begin{array}{l}\text { Community college or } \\
\text { Bible college }\end{array}$ & 20.03 & 5.63 & & \\
\hline Bachelor's degree & 20.87 & 5.77 & & \\
\hline Master's degree & 21.66 & & & \\
\hline Doctorate & 22.25 & 4.60 & & \\
\hline \multicolumn{5}{|l|}{ \# of close friends } \\
\hline 0 & 17.92 & 5.70 & 3.62 & $<.01$ \\
\hline 1 & 20.03 & 5.86 & & \\
\hline 2 & 20.97 & 5.58 & & \\
\hline 3 & 21.09 & 5.81 & & \\
\hline 4 or more & 21.44 & 5.45 & & \\
\hline
\end{tabular}


variables, the present study represented a similar group of clergy to these studies in terms of a sample which was predominantly White, male, and married with a mean age in the lower $50 \mathrm{~s}$. Milstein et al. (2019) reported a mean PHQ-9 score of $4.3(\mathrm{SD}=4.2)$, which was similar to the findings of the present study (mean PHQ-9=4.56, SD =4.47). As cited in the literature review, Proeschold-Bell et al. (2013) found $11.1 \%$ were currently experiencing major depression while Knox et al. (2002) found rates closer to $20 \%$ for Catholic clergy. Tanner and Zvonkovic (2011) found that about $40 \%$ of clergy had "some" depression symptoms. The present study found that $14.1 \%$ of the sample of Assemblies of God pastors had moderate depression or worse, while an additional $25.7 \%$ were experiencing mild depression symptoms. These findings align very closely to the cited studies.

On the variable of occupational distress, measured by the CODI, Milstein et al. (2019) reported a mean score of $6.6(\mathrm{SD}=3.0)$, which was similar to the present findings (mean $\mathrm{CODI}=6.82, \mathrm{SD}=3.13$ ). While CODI mean scores could not be compared with Frenk et al. (2013) due to scoring differences, it is noteworthy that their sample had $8 \%$ in the high range (fairly often or very often on all five items) and the present study had $20.5 \%$ in the high range. This difference could be the result of data collection during the COVID-19 pandemic. Regarding clergy spiritual well-being, there is no available data on categorical ranges for this scale. Future research can use or adapt the ranges provided in this study for comparison purposes.

The interconnected nature of the well-being variables was not surprising, but certainly noteworthy. The finding that occupational distress and spiritual well-being in daily life are predictors of depression suggests that depression symptoms may be prevented or reduced with improved management of occupational distress and personal spiritual vitality. Those who lead denominations, seminaries, and clergy training programs may increase their emphasis on stress management and personal spiritual practices in the life of the minister.

\section{Attitudes Toward Seeking Professional Counseling}

The significant predictors of attitudes toward seeking professional counseling suggest that there are ways to strategically target interventions for pastors in order to improve help-seeking. General continuing education for pastors could be a way to improve openness to help-seeking, which increased with education level. Integrating professional counselors into the seminary or Bible college setting could introduce pastors-in-training to the benefits of counseling and normalize help-seeking. Shifting traditional views of male role norms could also help connect help-seeking with a male identity. Such a shift may also be possible if educational and prevention tools teach pastors to develop cognitive flexibility.

Help-seeking attitudes were more positive with increased numbers of friends. Thus, helping pastors increase their number of close friends could improve attitudes toward seeking professional counseling and likely help them in other ways as well. This goal could be accomplished by awareness-raising as well as offering more social functions for pastors within each Assemblies of God district. Additionally, 
occupational distress predicted help-seeking attitudes, with higher distress relating to more positive views of counseling. This finding may suggest that pastors are more likely to wait to seek help until their distress is notably high. Assemblies of God district leaders could use the Clergy Occupational Distress Index as a regularly administered screening tool to assist pastors prior to crisis. Finally, because positive religious coping was predictive of positive attitudes toward seeking counseling, providing training on positive religious coping and holistic self-care could improve attitudes toward seeking professional counseling in addition to improving overall well-being as mentioned earlier.

\section{Strengths and Limitations of the Study}

This study offers findings gathered from a large, national sample of Assemblies of God clergy, which is the largest and most geographically broad study of its kind to date on this denomination. We intentionally chose instruments used by the Duke Clergy Health Initiative in order to offer direct comparisons with United Methodist clergy studies. Studies on Catholic clergy well-being have used similar types of instruments as well. This study contributes a new point of comparison and adds to the literature on clergy well-being.

This project targeted only pastors within the Assemblies of God and may not be generalizable to all ministers or clergy, even within the USA. As was mentioned in the discussion of the demographics of Assemblies of God pastors in the USA, this population is heavily weighted toward a White, married male demographic despite intentional effort to gain cooperation from non-White language districts. Because the survey items were only validated in English, the language districts were unable to distribute the survey in their native languages.

Further, the results of the present study are limited to the scales chosen, which may preclude other factors from being discovered. For example, self-stigma has been found to be a mediator between male role ideology and help-seeking attitudes (Levant et al., 2013), but this variable was not included in the present study due to limitations in survey length.

Finally, due to the coronavirus pandemic, only online means were available for obtaining survey results. Prior to the pandemic, the lead researcher had planned to attend Assemblies of God clergy events to obtain in-person survey responses as well. An additional consideration is that data collection during the pandemic (June 2020 to December 2020) may have shifted some of the results, such as elevating levels of depression or occupational distress.

\section{Recommendations for Future Research}

Further research is needed to determine more specific patterns of coping and helpseeking among clergy. While this study offered some data regarding pastors' helpseeking attitudes, it did not offer enough information related to pastors' motivations for seeking or not seeking help. A path analysis could shed more light on the decision-making factors that lead to seeking professional counseling. Such research 
could help denominational leaders identify effective prevention and intervention strategies before and during clergy distress.

Additional research is also needed within other conservative Protestant denominations. This study could be replicated within the Southern Baptist Convention to compare data, as it is another large denomination within the USA that has not been evaluated on well-being and help-seeking measures. Such data could also be compared with previous studies on the United Methodist Church.

Lastly, interventions that may improve pastors' well-being and attitudes toward seeking professional counseling can be developed and tested using pretest/posttest measures. Rather than simply attempting to help in a one-off approach, the Assemblies of God or other denominations could support the development of evidencebased interventions for clergy that can be replicated across regions and districts. Denominational leaders and district/regional leaders could be trained on these evidence-based models to increase accessibility and reduce costs.

\section{Conclusion}

The present study has added to the literature on clergy well-being and help-seeking. It expanded upon the term "psychological help" to focus more specifically on professional counseling and validated an adapted form of the widely used ATSPPH-SF scale. Overall, the pastors within the Assemblies of God are similar in demographic and well-being as compared to United Methodist clergy. Additional research is needed within other denominations. A variety of factors were predictive of attitudes toward seeking professional counseling, including age, gender, marital status, education level, number of close friends, views on male role norms, occupational distress, and use of positive religious coping. These data, along with descriptive information about barriers to counseling and use of mental health resources, shed light on possible interventions that can improve clergy well-being and help-seeking.

\section{Appendix A}

Attitudes Toward Seeking Professional Counseling (ATSPC) Scale.

This scale is an adapted version of the Attitudes Toward Seeking Professional Psychological Help, Short Form (ATSPPH-SF) scale (Fischer \& Farina, 1995) and was influenced by similar adaptations made by Simpson (2006). This version of the scale had a Chronbach's alpha of 0.84 in the present study.

\section{Select the answer that best describes how you feel:}

(Likert scale: 0-Disagree, 1—Partly disagree, 2-Partly agree, 3-Agree).

1. If I believed I was having a mental breakdown, my first inclination would be to get professional counseling. 
2. The idea of talking about problems with a professional counselor strikes me as a poor way to get rid of emotional conflicts.

3. If I were experiencing a serious emotional crisis at this point in my life, I would be confident that I could find relief in professional counseling.

4. There is something admirable in the attitude of a person who is willing to cope with his or her conflicts without resorting to professional counseling.

5. I would want to get professional counseling if I were worried or upset for a long period of time.

6. I might want to have professional counseling in the future.

7. A person with an emotional problem is not likely to solve it alone; he or she is likely to solve it with professional counseling.

8. Considering the time and expense involved in professional counseling, it would have doubtful value for a person like me.

9. A person should work out his or her own problems; getting professional counseling would be a last resort.

10. Personal and emotional troubles, like many things, tend to work out by themselves.

Reverse score items 2, 4, 8, 9, and 10 .

Author Contribution K.K. developed the research ideas and completed all data collection and manuscript writing. J.S. chaired the dissertation committee and provided overall guidance and feedback on the project. D.H., D.L., and M.N. provided feedback and editorial oversight as dissertation committee members.

Funding No funding was received for conducting this study.

Data availability The data that support the findings of this study are available from the corresponding author upon reasonable request.

Code Availability Not applicable.

\section{Declarations}

Conflicts of interest The first author K.K. holds credentials with the Assemblies of God as a licensed minister. The authors have no relevant financial interests to disclose.

\section{References}

Assemblies of God. (2017). 2017 ministers by race 2001 through 2017. Retrieved February 15, 2020, from https://ag.org/About/Statistics

Assemblies of God. (2018). 2018 ministers credentials and marital and ministry status by gender. Retrieved February 15, 2020, from https://ag.org/About/Statistics

Bickerton, G. R., Miner, M. H., Dowson, M., \& Griffin, B. (2015). Spiritual resources as antecedents of clergy well-being: The importance of occupationally specific variables. Journal of Vocational Behavior, 87, 123-133. https://doi.org/10.1016/j.jvb.2015.01.002

Chen, D. K. (2020). Pastoral identity, calling, burnout, and resilience (Publication No. 22589868) [Doctoral dissertation, Fuller Theological Seminary]. ProQuest Dissertations and Theses Global. 
Elhai, J. D., Schweinle, W., \& Anderson, S. M. (2008). Reliability and validity of the Attitudes Toward Seeking Professional Psychological Help Scale-Short Form. Psychiatry Research, 159(3), 320-329. https://doi.org/10.1016/j.psychres.2007.04.020

Ellison, C. G., Roalson, L. A., Guillory, J. M., Flannelly, K. J., \& Marcum, J. P. (2010). Religious resources, spiritual struggles, and mental health in a nationwide sample of PCUSA clergy. Pastoral Psychology, 59(3), 287-304. https://doi.org/10.1007/s11089-009-0239-1

Fischer, E. H., \& Farina, A. (1995). Attitudes toward seeking professional psychological help: A shortened form and considerations for research. Journal of College Student Development, 36(4), 368-373.

Frenk, S. M., Mustillo, S. A., Hooten, E. G., \& Meador, K. G. (2013). The clergy occupational distress index (CODI): background and findings from two samples of clergy. Journal of Religion and Health, 52(2), 397-407. https://doi.org/10.1007/s10943-011-9486-4

Good, G. E., Dell, D. M., \& Mintz, L. B. (1989). Male role and gender role conflict: Relations to help seeking in men. Journal of Counseling Psychology, 36(3), 295-300. https://doi.org/10.1037/00220167.36.3.295

Good, G. E., \& Wood, P. K. (1995). Male gender role conflict, depression, and help seeking: Do college men face double jeopardy? Journal of Counseling \& Development, 74(1), 70-75. https://doi.org/10. 1002/j.1556-6676.1995.tb01825.x

Grcevich, S. (2018). Mental health and the church: A ministry handbook for including families and children impacted by ADHD, anxiety disorders, and other common mental health conditions. Zondervan.

Hendron, J. A., Irving, P., \& Taylor, B. (2012). The unseen cost: A discussion of the secondary traumatization experience of the clergy. Pastoral Psychology, 61(2), 221-231. https://doi.org/10.1007/ s11089-011-0378-Z

Knox, S., Virginia, S. G., \& Lombardo, J. P. (2002). Depression and anxiety in Roman Catholic secular clergy. Pastoral Psychology, 50(5), 345-358. https://doi.org/10.1023/A:1014461603872

Kroenke, K., Spitzer, R. L., \& Williams, J. B. (2001). The PHQ-9: Validity of a brief depression severity measure. Journal of General Internal Medicine, 16(9), 606-613. https://doi.org/10.1046/j.15251497.2001.016009606.x

LCR. (2015). Lifeway Christian Resources - Mental Health and the Church. Facts and Trends, December 2014-February 2015, pp. 1-51. https://lifewayresearch.com/wp-content/uploads/2014/11/FTWin ter2015-smaller.pdf

Lee, C., \& Iverson-Gilbert, J. (2003). Demand, support, and perception in family-related stress among Protestant clergy. Family Relations, 52(3), 249-257. https://doi.org/10.1111/j.1741-3729.2003. 00249.x

Levant, R. F., Stefanov, D. G., Rankin, T. J., Halter, M. J., Mellinger, C., \& Williams, C. M. (2013). Moderated path analysis of the relationships between masculinity and men's attitudes toward seeking psychological help. Journal of Counseling Psychology, 60(3), 392-406. https://doi.org/10.1037/ a0033014

Levant, R. F., Wimer, D. J., \& Williams, C. M. (2011). An evaluation of the health behavior inventory-20 (HBI-20) and its relationships to masculinity and attitudes towards seeking psychological help among college men. Psychology of Men \& Masculinity, 12(1), 26-41. https://doi.org/10.1037/a0021 014

Levant, R. F., Wimer, D. J., Williams, C. M., Smalley, K. B., \& Noronha, D. (2009). The relationships between masculinity variables, health risk behaviors and attitudes toward seeking psychological help. International Journal of Men's Health, 8(1), 3-21.

McDermott, R. C., Levant, R. F., Hammer, J. H., Borgogna, N. C., \& McKelvey, D. K. (2019). Development and validation of a five-item Male Role Norms Inventory using bifactor modeling. Psychology of Men \& Masculinities, 20(4), 467-477. https://doi.org/10.1037/men0000178

McMinn, M. R., Lish, R. A., Trice, P. D., Root, A. M., Gilbert, N., \& Yap, A. (2005). Care for pastors: Learning from clergy and their spouses. Pastoral Psychology, 53(6), 563-581. https://doi.org/10. 1007/s11089-005-4821-y

Meek, K. R., Mcminn, M. R., Brower, C. M., Burnett, T. D., Mcray, B. W., Ramey, M. L., Swanson, D. W., \& Villa, D. D. (2003). Maintaining personal resiliency: Lessons learned from evangelical Protestant clergy. Journal of Psychology and Theology, 31(4), 339-347. https://doi.org/10.1177/00916 4710303100404 
Miles, A., \& Proeschold-Bell, R. J. (2013). Overcoming the challenges of pastoral work? Peer support groups and psychological distress among united Methodist church clergy. Sociology of Religion, 74(2), 199-226. https://doi.org/10.1093/socrel/srs055

Milstein, G., Hybels, C. F., \& Proeschold-Bell, R. J. (2019). A prospective study of clergy spiritual wellbeing, depressive symptoms, and occupational distress. Psychology of Religion and Spirituality. https://doi.org/10.1037/re10000252

Pargament, K., Feuille, M., \& Burdzy, D. (2011). The brief RCOPE: Current psychometric status of a short measure of religious coping. Religions, 2(1), 51-76. https://doi.org/10.3390/rel2010051

Pargament, K. I., Tarakeshwar, N., Ellison, C. G., \& Wulff, K. M. (2001). Religious coping among the religious: The relationships between religious coping and well-being in a national sample of Presbyterian clergy, elders, and members. Journal for the Scientific Study of Religion, 40(3), 497-513. https://doi.org/10.1111/0021-8294.00073

Pooler, D. K. (2011). Pastors and congregations at risk: Insights from role identity theory. Pastoral Psychology, 60(5), 705-712. https://doi.org/10.1007/s11089-011-0356-5

Proeschold-Bell, R. J., LeGrand, S., James, J., Wallace, A., Adams, C., \& Toole, D. (2011). A theoretical model of the holistic health of United Methodist clergy. Journal of Religion and Health, 50(3), 700-720. https://doi.org/10.1007/s10943-009-9250-1

Proeschold-Bell, R. J., Miles, A., Toth, M., Adams, C., Smith, B. W., \& Toole, D. (2013). Using effortreward imbalance theory to understand high rates of depression and anxiety among clergy. The Journal of Primary Prevention, 34(6), 439-453. https://doi.org/10.1007/s10935-013-0321-4

Proeschold-Bell, R. J., Yang, C., Toth, M., Rivers, M. C., \& Carder, K. (2014). Closeness to God among those doing God's work: A spiritual well-being measure for clergy. Journal of Religion and Health, 53(3), 878-894. https://doi.org/10.1007/s10943-013-9682-5

Shirey, E. L., Jr. (2001). The use of support systems by pastors of the International Pentecostal Holiness Church as a means of maintaining spiritual well-being and coping with burnout (Publication No. 3013569) [Doctoral dissertation, Asbury Theological Seminary]. ProQuest Dissertations and Theses Global.

Siebert, D., \& Siebert, C. (2005). The caregiver role identity scale: A validation study. Research on Social Work Practice, 15(3), 204-212. https://doi.org/10.1177/1049731504272779

Siebert, D., \& Siebert, C. (2007). Help seeking among helping professionals: A role identity perspective. American Journal of Orthopsychiatry, 77(1), 49-55. https://doi.org/10.1037/0002-9432.77.1.49

Simpson, A. M. (2006). The relationship between racial identity and attitudes towards seeking professional psychological help (Publication No. 1440148) [Master's thesis, Southern Illinois University at Carbondale]. ProQuest Dissertations and Theses.

Tanner, M. N., \& Zvonkovic, A. M. (2011). Forced to leave: Forced termination experiences of Assemblies of God clergy and its connection to stress and well-being outcomes. Pastoral Psychology, 60(5), 713-726. https://doi.org/10.1007/s11089-011-0339-6

Trihub, B. L., Mcminn, M. R., Buhrow, W. C., Jr., \& Johnson, T. F. (2010). Denominational support for clergy mental health. Journal of Psychology and Theology, 38(2), 101-110. https://doi.org/10.1177/ 009164711003800203

Visker, J. D., Rider, T., \& Humphers-Ginther, A. (2017). Ministry-related burnout and stress coping mechanisms among Assemblies of God-ordained clergy in Minnesota. Journal of Religion and Health, 56(3), 951-961. https://doi.org/10.1007/s10943-016-0295-7

Williams, C. (2019). Psychological well-being, occupational thriving, and positive interpersonal relationships (Publication No. 10840656) [Doctoral dissertation, Fuller Theological Seminary]. ProQuest Dissertations and Theses Global.

Publisher's Note Springer Nature remains neutral with regard to jurisdictional claims in published maps and institutional affiliations. 